\title{
Survivin, Ki-67 and tumor grade as predictors of response to docetaxel-based neoadjuvant chemotherapy in locally advanced breast cancer
}

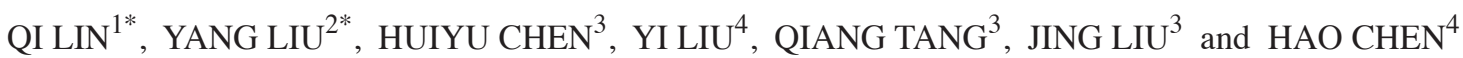 \\ ${ }^{1}$ Department of General Surgery, Zhongshan Hospital Affiliated to Fudan University, Shanghai 200032; \\ Departments of ${ }^{2}$ Ultrasonography, ${ }^{3}$ General Surgery and ${ }^{4}$ Pathology, Lianyungang First People's Hospital \\ Affiliated to Xuzhou Medical College, Lianyungang, Jiangsu 222002, P.R. China
}

Received March 15, 2013; Accepted June 10, 2013

DOI: $10.3892 / \mathrm{mco} .2013 .138$

\begin{abstract}
The response rates to neoadjuvant chemotherapy (NAC) in patients with locally advanced breast cancer (LABC) may vary and the risks may outweigh the benefits in poorly selected patients. This study investigated whether survivin expression, high-level Ki-67 expression, estrogen-receptor (ER) tumor status and high tumor grade are able to predict response to docetaxel-based NAC in LABC patients, in order to perform breast-conserving surgery. In this study, 68 patients (IIb-IIIb) completed $4-6$ cycles of TAC $\left(75 \mathrm{mg} / \mathrm{m}^{2}\right.$ docetaxel, $60 \mathrm{mg} / \mathrm{m}^{2}$ pirarubicin and $500 \mathrm{mg} / \mathrm{m}^{2}$ cyclophosphamide, administered every 3 weeks). Tumor samples were obtained prior to chemotherapy. The response to chemotherapy was quantified clinically and pathologically and the histological and molecular tumor characteristics were determined. Association with response was assessed for all the parameters and the patients underwent breast-conserving surgery or radical mastectomy accordingly. A clinical complete response was observed in $21(31 \%)$ and a partial response in 37 (54\%) of the 68 patients. Thus, the overall clinical response rate (ORR) was $85 \%$. A pathological complete response (pCR) was observed in $14(20 \%)$ of the 68 patients and 37 patients (54\%) underwent breast-conserving surgery. In the univariate analysis, survivin expression, high-level Ki-67 expression and high tumor grade (grade III) were significantly associated with ORR ( $\mathrm{P}=0.007,0.024$ and 0.047 , respectively). Survivin expression and high-level Ki-67 expression were significantly associated with $\mathrm{pCR}(\mathrm{P}=0.029$ and 0.048 , respectively). In the multivariate analysis, survivin expression $(\mathrm{P}=0.030)$ and tumor grade $(\mathrm{P}=0.036)$, but not high-level Ki-67
\end{abstract}

Correspondence to: Dr Qi Lin, Department of General Surgery, Zhongshan Hospital Affiliated to Fudan University, 180 Fenglin Road, Shanghai 200032, P.R. China

E-mail: 12111210046@fudan.edu.cn

*Contributed equally

Key words: breast cancer, neoadjuvant chemotherapy, predictive factors, docetaxel-based chemotherapy regimen and ER expression, were significantly associated with ORR and none of these factors was significantly associated with pCR. In conclusion, expression of survivin and high tumor grade were of predictive value for ORR to docetaxel-based NAC in LABC patients, leading to more patients successfully undergoing breast conserving-surgery. Immunohistochemistry of survivin and the Elston and Ellis criteria of tumor grade may provide a widely applicable, cost-effective method of patient selection for NAC.

\section{Introduction}

The response rates to neoadjuvant chemotherapy (NAC) in patients with locally advanced breast cancer (LABC) are 40-60\%. The drawbacks of this treatment method are that certain patients may experience adverse effects and that it may cause unnecessary delay to surgical treatment, particularly in the cases with progressive disease. Therefore, biomarkers that predict response to NAC may prove useful. The most important qualities for a biomarker are that it may be assessed easily and at low cost, even in hospitals that lack expensive laboratory equipment and advanced molecular techniques. Previous studies demonstrated that gene microarray technologies are able to predict response to NAC $(1,2)$. However, this advanced technique has not been routinely applied in the clinical setting due to its high cost, particularly in developing countries and low-income areas.

An increasing number of studies investigate factors [including survivin, Ki-67, estrogen-receptor (ER) tumor status and tumor grade] that may predict response to either first- or second-line chemotherapy. However, available data on the prediction of the efficacy of third-line chemotherapeutic agents (i.e., those including anthracyclines and either docetaxel or dose-dense weekly paclitaxel) are limited. The aim of this study was to investigate whether survivin, Ki-67, ER tumor status and tumor grade are useful predictive biomarkers for the response of the primary tumor to NAC with a docetaxel-based regimen.

We considered a regimen of $75 \mathrm{mg} / \mathrm{m}^{2}$ docetaxel, $60 \mathrm{mg} / \mathrm{m}^{2}$ pirarubicin and $500 \mathrm{mg} / \mathrm{m}^{2}$ cyclophosphamide (TAC) once every 3 weeks to be an effective option for NAC in LABC, 
in order that more patients benefit from undergoing breast conserving-surgery following treatment. Survivin expression and high tumor grade were shown to be independent predictors of response.

\section{Materials and methods}

Patients. Between January, 2009 and December, 2012, 71 patients with locally advanced (stage IIb and IIIb) breast cancer were enrolled at Lianyungang First People's Hospital (Jiangu, China). Eligible patients had core needle biopsy-confirmed breast cancer, were previously untreated and had locally advanced tumors that were potentially operable, without evidence of distant metastasis (Table I). Three patients did not complete the chemotherapy scheme due to the development of leukopenia and asthenia.

This study was conducted in accordance with the ethics principles of the Declaration of Helsinki. The study methods were approved by the Institutional Review Board of Lianyungang First People's Hospital and patients provided written informed consent prior to enrollment.

Treatment. Prior to treatment initiation, tumors were measured by magnetic resonance imaging (MRI). Patients received the TAC regime, administered every 3 weeks for 4-6 cycles. Patients were administered dexamethasone premedication $(8 \mathrm{mg}$ orally every $12 \mathrm{~h}, 6$ times, starting the day prior to treatment initiation) to prevent docetaxel-related hypersensitivity and fluid retention. Primary prophylaxis with granulocyte colony-stimulating factor (G-CSF) was not permitted. However, in patients who developed episodes of febrile neutropenia or infection, administration of G-CSF was mandatory in the subsequent cycles. Approximately 2 weeks after NAC, the patients underwent either breast-conserving surgery or modified radical mastectomy. Following surgery, the patients received chemotherapy, radiotherapy, endocrine therapy or a combination of these treatments.

Treatment response. The clinical treatment response was assessed using the Response Evaluation Criteria in Solid Tumors (RECIST) (3). The overall clinical response rate (ORR) was defined as the complete and partial responses combined. The pathological complete response (pCR) was assessed after surgical resection of the remaining tumor and nodes and was defined as the absence of tumor cells, absence of persistent in situ disease and negative axillary lymph nodes. All samples were assessed by two pathologists at Lianyungang First People's Hospital.

Evaluation of survivin, Ki-67 and ER tumor status. Core biopsy specimens were fixed in $10 \%$ neutral-buffered formalin for $24 \mathrm{~h}$ prior to processing and embedded in paraffin wax blocks at the pathology laboratory in our hospital. Sections $(3 \mathrm{~mm})$ were cut from each block, mounted on positively-charged slides and stained with hematoxylin and eosin.

Prior to immunohistochemical analysis, the tissue sections were deparaffinized and rehydrated in graded alcohols. The slides were subjected to heat-induced epitope retrieval by immersion in $0.01 \mathrm{M}$ boiling citrate buffer $(\mathrm{pH} 6)$ in a pressure cooker for $3 \mathrm{~min}$, followed by a 20 -min cooling period and

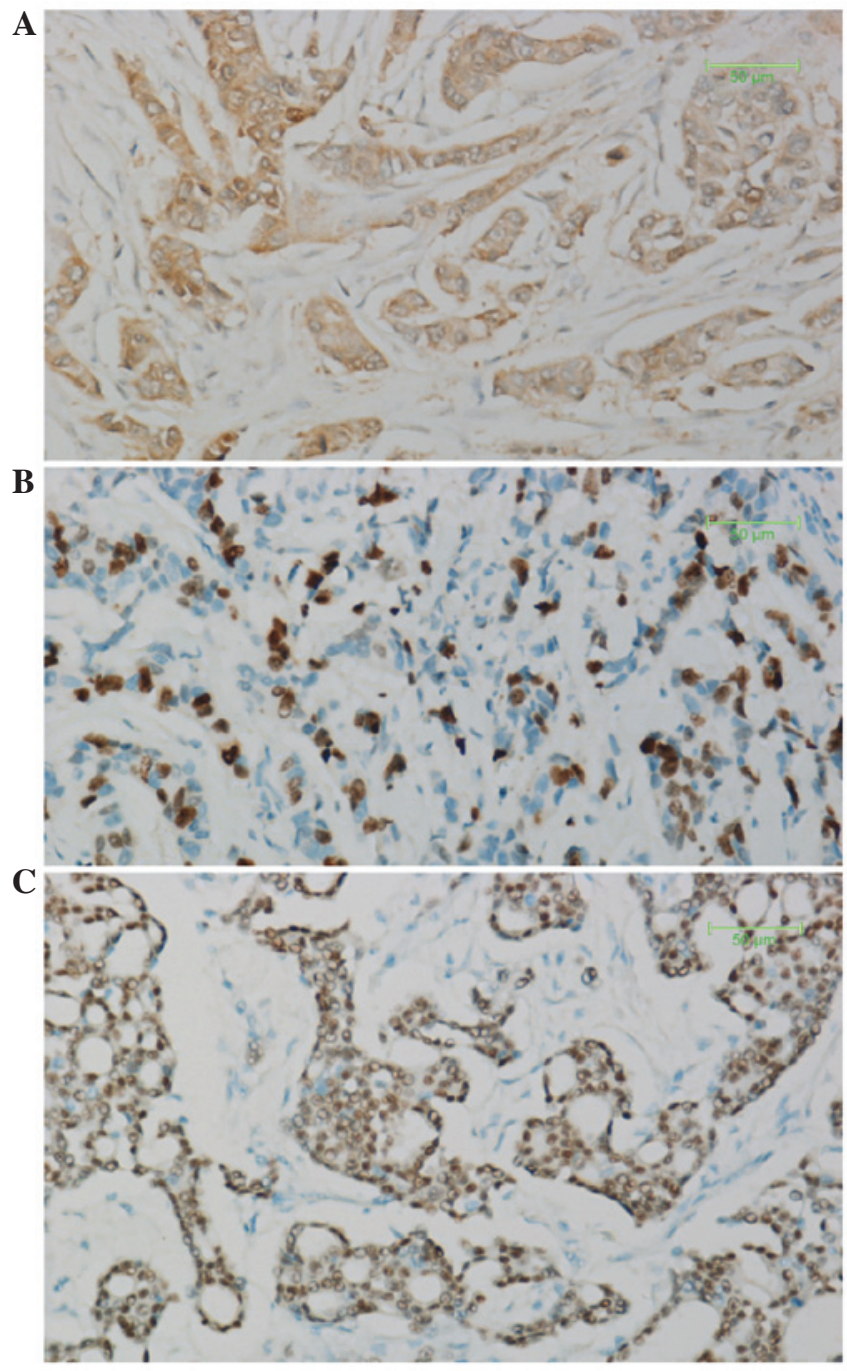

Figure 1. Immunohistochemistry results. (A) Survivin cytoplasmic expression. (B) Ki-67 nuclear expression. (C) Estrogen-receptor nuclear expression. Magnification, $\mathrm{x} 200$.

overnight incubation with monoclonal antibody [rabbit monoclonal anti-survivin (1:100, cat no: Z2159; Reta Corporation, Deerfield Beach, FL, USA), rabbit monoclonal anti-Ki-67 (1:100, cat no: Z2031; Reta Corporation) and rabbit monoclonal anti-ER (1:200, cat no: Z2021RS; Reta Corporation)]. Negative and positive control slides were also prepared. Histological classification was performed according to the WHO criteria and tumor grading was performed according to the Elston and Ellis criteria (4).

Survivin expression was semi-quantitatively evaluated according to the percentage of cells with nuclear and/or cytoplasmic reactions. Immunoreactivity was assessed in at least five high-power fields at a magnification of x 200 and scores were classified as follows: $0,<5 \%$ of tumor cells stained; $1,5-20 \%$ of tumor cells stained; and $2,>20 \%$ of tumor cells stained. A score of 2 was considered as positive and scores of 0 or 1 were considered negative (Fig. 1A) (5). For Ki-67, nuclear staining in $>20 \%$ of the tumor cells was considered to indicate high-level expression (Fig. 1B). Tumors were classified as ER-positive when nuclear staining was visible in $\geq 10 \%$ of the tumor cells (Fig. 1C) (6). 
Table I. Univariate analysis of the association of baseline characteristics with ORR and pCR.

\begin{tabular}{|c|c|c|c|c|c|}
\hline Characteristics & No. & ORR & P-value & $\mathrm{pCR}$ & P-value \\
\hline No. of patients & 68 & & & & \\
\hline Median age, years (range) & $45(35-60)$ & & & & \\
\hline Tumor diameter, mm (range) & $45(25-80)$ & & & & \\
\hline \multicolumn{6}{|l|}{ Menopausal status } \\
\hline Premenopausal & 32 & $81 \%(26 / 32)$ & $0.587^{\mathrm{a}}$ & $19 \%(6 / 32)$ & $0.724^{\mathrm{a}}$ \\
\hline Postmenopausal & 36 & $86 \%(31 / 36)$ & & $22 \%(8 / 36)$ & \\
\hline \multicolumn{6}{|l|}{ ECOG performance } \\
\hline 0 & 44 & $86 \%(38 / 44)$ & $0.670^{\mathrm{b}}$ & $23 \%(10 / 44)$ & $0.782^{\mathrm{b}}$ \\
\hline 1 & 24 & $79 \%(19 / 24)$ & & $17 \%(4 / 24)$ & \\
\hline \multicolumn{6}{|l|}{ Clinical nodal status } \\
\hline Negative & 18 & $78 \%(14 / 18)$ & $0.661^{\mathrm{b}}$ & $17 \%(3 / 18)$ & $0.889^{\mathrm{b}}$ \\
\hline Positive & 50 & $86 \%(43 / 50)$ & & $22 \%(11 / 50)$ & \\
\hline \multicolumn{6}{|l|}{ Stage } \\
\hline II $(\mathrm{T} \geq 5 \mathrm{~cm})$ & 30 & $80 \%(24 / 30)$ & $0.668^{\mathrm{b}}$ & $20 \%(6 / 30)$ & $0.915^{\mathrm{a}}$ \\
\hline III & 38 & $87 \%(33 / 38)$ & & $21 \%(8 / 38)$ & \\
\hline \multicolumn{6}{|l|}{ Survivin } \\
\hline Negative & 18 & $61 \%(11 / 18)$ & $0.0072^{c}$ & $0 \%(0 / 18)$ & $0.0292^{\mathrm{a}}$ \\
\hline Positive & 50 & $92 \%(46 / 50)$ & & $28(14 / 50)$ & \\
\hline \multicolumn{6}{|l|}{ Ki-67 } \\
\hline Negative & 16 & $63 \%(10 / 16)$ & $0.0242^{\mathrm{c}}$ & $0 \%(0 / 16)$ & $0.0482^{\mathrm{a}}$ \\
\hline Positive & 52 & $90 \%(47 / 52)$ & & $27 \%(14 / 52)$ & \\
\hline \multicolumn{6}{|l|}{ Estrogen-receptor } \\
\hline Negative & 31 & $87 \%(27 / 31)$ & $0.502^{\mathrm{a}}$ & $29 \%(8 / 31)$ & $0.330^{\mathrm{a}}$ \\
\hline Positive & 37 & $81 \%(30 / 37)$ & & $16 \%(6 / 37)$ & \\
\hline \multicolumn{6}{|l|}{ No. of cycles } \\
\hline 4 & 39 & $85 \%(33 / 39)$ & $1.0^{\mathrm{b}}$ & $21 \%(8 / 39)$ & $0.986^{\mathrm{a}}$ \\
\hline $5-6$ & 29 & $83 \%(24 / 29)$ & & $21 \%(6 / 29)$ & \\
\hline \multicolumn{6}{|l|}{ Tumor type } \\
\hline Invasive ductal & 60 & $87 \%(52 / 60)$ & $0.218^{\mathrm{b}}$ & $25 \%(13 / 60)$ & $0.891^{\mathrm{b}}$ \\
\hline Invasive lobular & 8 & $63 \%(5 / 8)$ & & $13 \%(1 / 8)$ & \\
\hline \multicolumn{6}{|l|}{ Tumor grade } \\
\hline $\mathrm{I} / \mathrm{II}$ & 28 & $71 \%(20 / 28)$ & $0.0472^{\mathrm{c}}$ & $11 \%(3 / 28)$ & $0.092^{\mathrm{a}}$ \\
\hline III & 40 & $93 \%(37 / 40)$ & & $28 \%(11 / 40)$ & \\
\hline \multicolumn{6}{|l|}{$\mathrm{PgR}$} \\
\hline Negative & 37 & $28 \%(11 / 40)$ & $0.189^{\mathrm{a}}$ & $22 \%(8 / 37)$ & $0.818^{\mathrm{a}}$ \\
\hline Positive & 31 & $77 \%(24 / 31)$ & & $19 \%(6 / 31)$ & \\
\hline \multicolumn{6}{|l|}{ HER2 status } \\
\hline 0 to $1+$ & 50 & $88 \%(44 / 50)$ & $0.236^{\mathrm{b}}$ & $24 \%(12 / 50)$ & $0.412^{\mathrm{b}}$ \\
\hline $2+$ to $3+$ & 18 & $72 \%(13 / 18)$ & & $17 \%(2 / 18)$ & \\
\hline
\end{tabular}

${ }^{\mathrm{a}} \mathrm{P}$, Pearson's Chi-square test, ${ }^{\mathrm{b}} \mathrm{P}$, continuity correction test, ${ }^{\mathrm{C}} \mathrm{P}<0.05$. ORR, overall clinical response rate; $\mathrm{pCR}$, pathological complete response; PgR, progesterone receptor. ECOG, Eastern cooperative oncology group; HER2, human epidermal growth factor receptor-2.

Statistical analysis. The primary endpoint was to assess the predictive value of survivin, Ki-67, ER-negative tumor status and tumor grade for the ORR to docetaxel-based NAC in patients with $\mathrm{LABC}$, to enhance the breast-conserving surgery rate with docetaxel-based NAC. The effects of survivin, $\mathrm{Ki}-67, \mathrm{ER}$ tumor status and tumor grade on the response to NAC and the correlations between survivin, Ki-67 and ER tumor status were assessed with the Pearson's Chi-square test 
Table II. Multivariate analysis of the association of protein expressions with ORR and $\mathrm{pCR}$.

\begin{tabular}{lccc}
\hline $\begin{array}{l}\text { Predictive } \\
\text { markers }\end{array}$ & Odds ratio & $95 \%$ CI & P-value \\
\hline $\begin{array}{l}\text { Survivin } \\
\text { ORR }\end{array}$ & 5.879 & $1.185-29.178$ & $0.030^{\mathrm{a}}$ \\
pCR & 3.652 & $0-0$ & 0.998 \\
Ki-67 & & & \\
ORR & 3.012 & $0.647-14.022$ & 0.160 \\
pCR & 2.359 & $0-0$ & 0.998 \\
Tumor grade & & & \\
ORR & 5.993 & $1.124-31.967$ & $0.036^{\mathrm{a}}$ \\
pCR & 0.254 & $0.537-10.474$ & 0.254 \\
PgR & 0.460 & $0.091-2.328$ & 0.348 \\
\hline
\end{tabular}

${ }^{\mathrm{a}} \mathrm{P}<0.05$. CI, confidence interval; ORR, overall clinical response rate; $\mathrm{pCR}$, pathological complete response; PgR, progesterone receptor.

(with a correction for continuity in comparisons with small numbers). Possible predictive factors associated with response probability at a significance level of $\leq 0.20$ were considered in a multivariable logistic regression analysis $(6) . \mathrm{P}<0.05$ was determined as the threshold for statistical significance and all P-values were two-tailed. Data were analyzed with SPSS software for Windows version 16.0 (SPSS Inc., Chicago, IL, USA).

\section{Results}

Tumor response. MRI revealed that $21(31 \%)$ of the 68 patients exhibited a clinical complete response and $37(54 \%)$ exhibited a partial response. Therefore, the ORR was $85 \%$. The disease was classified as stable in $11(16.2 \%)$ of the 68 patients and no patient had progressive disease. pCR was confirmed in $14(20 \%)$ of the 68 patients and 37 patients (54\%) underwent breast-conserving surgery.

Predictive value of survivin, Ki-67, ER status and tumor grade. Of the 68 breast carcinomas, survivin expression was detected in 50 (74\%), with no expression observed in the adjacent normal tissue. High-level expression of Ki-67 was detected in $52(77 \%)$ tumors and a ER-negative status was detected in $31(46 \%)$ tumors. A total of 40 tumors (59\%) were high-grade (grade III) and the remaining 28 (41\%) were grade $\mathrm{I} / \mathrm{II}$.

In the univariate analysis, survivin expression, high-level Ki-67 expression and high tumor grade (grade III) were significantly associated with ORR $(\mathrm{P}=0.007,0.024$ and 0.047 , respectively). Survivin expression and high-level Ki-67 expression were significantly associated with $\mathrm{pCR}(\mathrm{P}=0.029$ and 0.048 , respectively) (Table I). In the multivariate analysis, survivin expression and high tumor grade, but not high-level Ki-67 expression, were significantly associated with ORR $(\mathrm{P}=0.030$ and 0.036 , respectively) and none of the factors was significantly associated with pCR (Table II).
Correlation between biomarkers. A strong correlation was observed between the expression of survivin and the high-level expression of $\mathrm{Ki}-67(\mathrm{P}=0.034)$. It was not possible to clearly determine a correlation between survivin expression and ER-positive tumor status $(\mathrm{P}=0.223)$ or an inverse correlation between high-level Ki-67 expression and ER-positive tumor status $(\mathrm{P}=0.059)$.

\section{Discussion}

Breast cancer is the most common cancer among women. NAC may lead to tumor downstaging and increase the likelihood of patients undergoing successful breast-conserving surgery. However, the benefits depend on the selection of the most effective chemotherapy regimens. Doctors commonly select regimens on the basis of clinical and histological characteristics and treatment is generally not individualized. Therefore, numerous patients may receive unnecessary or ineffective NAC, which may lead to toxic effects, increased cost, delay to curative treatment and tumor cross-resistance (7). Thus, methods to facilitate the selection of the most effective regimens are urgently needed.

Anthracycline-based regimens for breast cancer achieve high response rates. A widely used regimen for breast cancer NAC is combined cyclophosphamide, doxorubicin and fluorouracil; however, resistance to this regimen has emerged. Previous trials reported good response rates with taxane-containing regimens $(8,9)$. Docetaxel has exhibited high activity in combination with doxorubicin, including in patients with anthracycline-resistant disease. Nabholtz et al (10) reported that patients with metastatic breast cancer treated with combined docetaxel and doxorubicin exhibited significantly improved ORRs compared to those of patients treated with doxorubicin and cyclophosphamide. Mackey et al (11) provided evidence in their 10-year analysis of the randomised BCIRG 001 trial that TAC for the treatment of patients with node-positive, early breast cancer provides long-term disease-free survival and overall survival benefits compared to fluorouracil (5-FU), doxorubicin and cyclophosphamide (FAC), irrespective of nodal, hormone receptor and human epidermal growth factor receptor-2 (HER2) status.

Despite the improvements in ORR and the assessment of several chemotherapeutic regimens, the pCR rate following NAC for breast cancer remains low (12). Survival is significantly prolonged in patients who achieve pCR after NAC compared to those who do not $(13,14)$. This finding may, therefore, be used as a suitable surrogate endpoint for response in studies on NAC. In our study, after 4-6 cycles of the TAC regimen, the clinical CR rate was $31 \%$ and the pCR rate was $20 \%$. Moreover, our primary endpoint was breast-conserving surgery. This suggests that the TAC regimen may be effective as NAC for patients with LABC.

The survivin gene (BIRC5) is a member of the inhibitor of apoptosis protein family and has various functions: regulation of cell proliferation and division, inhibition of cell apoptosis and promotion of angiogenesis (15). Survivin expression was detected by immunohistochemistry in $60-70 \%$ of primary breast tumors, with little or no expression in control tissue samples. High expression of survivin has been correlated with poor clinical outcomes in breast, lung, prostate, pancreatic and 
colorectal cancers (16). Survivin may, therefore, be a potential prognostic factor, a predictive factor for response to treatment and a therapeutic target in breast cancer patients. In the univariate analysis, we observed a significant correlation of survivin expression with ORR and pCR to NAC. However, in the multivariate analysis, a significant correlation was observed only with ORR. Several studies reported that patients with a pCR following NAC exhibited higher survival rates compared to those without pCR $(13,14)$ and a high expression of survivin has been correlated with poor clinical outcomes $(15,16)$. Therefore, the results of a previous study by Petrarca et al (18), indicating that survivin may be a predictive biomarker of $\mathrm{pCR}$ to NAC in patients with stage II and III breast cancer, were not in accordance with our results and require further investigation. Another study reported that failure of the downregulation of survivin following neoadjuvant radiochemotherapy in rectal cancer was associated with distant metastases and shortened survival (17), although there was no report of the association with breast cancer.

Gerdes et al (19) previously used a mouse monoclonal antibody against a nuclear antigen from a Hodgkin's lymphoma cell line and identified $\mathrm{Ki}-67$ as a marker of cell proliferation. Ki-67 was universally expressed among proliferating cells and absent in quiescent cells. Several studies have since investigated the possible prognostic role for Ki-67 in breast cancer, with varying results. Urruticoechea et al (20) conducted a review of 40 studies involving $>11,000$ patients and reported that $\mathrm{Ki}-67$ expression alone is able to predict positive or negative outcomes in patients with node-negative breast cancer, although the predictive value was not maintained in multivariate analyses. de Azambuja et al (21) demonstrated that Ki-67 expression in node-negative and node-positive breast cancer was associated with poor overall and disease-free survival. The findings of Stuart-Harris et al (22) did not support Ki-67 as a prognostic marker for use in routine practice. Sánchez-Muñoz et al (13) identified the Ki-67 index as an independent prognostic factor for disease-free and overall survival in breast cancer patients treated with NAC. A high Ki-67 expression and hormone receptor-negative status were shown to be predictors of pCR. In the univariate, but not the multivariate, analysis we observed that a high-level expression of Ki-67 was significantly associated with good ORR and pCR to NAC, which may be attributed to our small study sample. Although it is disputable whether Ki-67 is an independent predictor or prognostic marker, a high expression of Ki-67 indicating good response to docetaxel-based NAC suggests that breast-conserving surgery may be performed in the high-expression patients.

ER and progesterone receptor $(\mathrm{PgR})$ status provides the index for sensitivity to endocrine treatment; therefore, it is the most important biomarker in breast cancer. Numerous studies identified ER and PgR as independent variables, significantly associated with the likelihood of achieving pCR $(23,24)$. However, the findings of our study, taken together with those of Wang et al (25), do not support this result. This discordance may be explained by the heterogeneity of the investigation methods, particularly the cut-offs used by various studies. In our study, the sample size was small and the detection of PgR expression was performed after the NAC, which may change the status and affect the result. We observed that high histological grade was a significant independent predictor of pCR in multivariate models with low-grade tumors, which is consistent with the findings of previous studies in multivariate models (6).

A good correlation was observed between survivin expression and high-level Ki-67 expression, similar to the findings of $\mathrm{Xu}$ et al (26). A previous study by Lee et al (27) reported an inverse correlation between high-level Ki-67 expression and ER-positive tumor status. However, our study did not support that result and whether survivin expression correlates with ER-positive tumor status could not be determined. This was not in accordance with the findings of Ryan et al (28), possibly due to their detection methods for protein quantification being more accurate.

In conclusion, a regimen of $75 \mathrm{mg} / \mathrm{m}^{2}$ docetaxel, $60 \mathrm{mg} / \mathrm{m}^{2}$ pirarubicin and $500 \mathrm{mg} / \mathrm{m}^{2}$ cyclophosphamide once every 3 weeks may be effective as NAC in LABC and more patients may benefit from undergoing breast conserving-surgery after the treatment. Survivin expression and high tumor grade were identified as independent predictors of response.

\section{Acknowledgements}

This study was supported by a grant from the Lianyungang Municipal Health Bureau (no. 09009). The authors would like to thank all the patients and their family members for their consent and cooperation, without them this study would not have been possible.

\section{References}

1. Ayers M, Symmans WF, Stec J, Damokosh AI, Clark E, Hess K, Lecocke M, Metivier J, Booser D, Ibrahim N, Valero V, Royce M, Arun B, Whitman G, Ross J, Sneige N, Hortobagyi GN and Pusztai L: Gene expression profiles predict complete pathologic response to neoadjuvant paclitaxel and fluorouracil, doxorubicin, and cyclophosphamide chemotherapy in breast cancer. J Clin Oncol 22: 2284-2293, 2004.

2. van't Veer LJ, Dai H, van de Vijver MJ, He YD, Hart AA, Mao M, Peterse HL, van der Kooy K, Marton MJ, Witteveen AT, Schreiber GJ, Kerkhoven RM, Roberts C, Linsley PS, Bernards R and Friend SH: Gene expression profiling predicts clinical outcome of breast cancer. Nature 415: 530-536, 2002.

3. Therasse P, Arbuck SG, Eisenhauer EA, Wanders J, Kaplan RS, Rubinstein L, Verweij J, Van Glabbeke M, van Oosterom AT, Christian MC and Gwyther SG: New guidelines to evaluate the response to treatment in solid tumors. European Organization for Research and Treatment of Cancer, National Cancer Institute of the United States, National Cancer Institute of Canada. J Natl Cancer Inst 92: 205-216, 2000.

4. Elston CW and Ellis IO: Pathological prognostic factors in breast cancer. I. The value of histological grade in breast cancer: experience from a large study with long-term follow-up. Histopathology 19: 403-410, 1991.

5. Asanuma H, Torigoe T, Kamiguchi K, Hirohashi Y, Ohmura T, Hirata K, Sato M and Sato N: Survivin expression is regulated by coexpression of human epidermal growth factor receptor 2 and epidermal growth factor receptor via phosphatidylinositol 3-kinase/AKT signaling pathway in breast cancer cells. Cancer Res 65: 11018-11025, 2005.

6. Petit T, Wilt M, Velten M, Millon R, Rodier JF, Borel C, Mors R, Haegelé P, Eber M and Ghnassia JP: Comparative value of tumor grade, hormonal receptors, Ki-67, HER-2 and topoisomerase II alpha status as predictive markers in breast cancer patients treated with neoadjuvant anthracycline-based chemotherapy. Eur J Cancer 40: 205-211, 2004.

7. Fuksa L, Micuda S, Grim J, Ryska A and Hornychova H: Predictive biomarkers in breast cancer: their value in neoadjuvant chemotherapy. Cancer Invest 30: 663-678, 2012. 
8. Cortes $\mathbf{J}$ and Roché $\mathrm{H}$ : Docetaxel combined with targeted therapies in metastatic breast cancer. Cancer Treat Rev 38: 387-396, 2012.

9. Belfiglio M, Fanizza C, Tinari N, Ficorella C, Iacobelli S and Natoli C: Meta-analysis of phase III trials of docetaxel alone or in combination with chemotherapy in metastatic breast cancer. J Cancer Res Clin Oncol 138: 221-229, 2012.

10. Nabholtz JM, Falkson C, Campos D, Szanto J, Martin M, Chan S, Pienkowski T, Zaluski J, Pinter T, Krzakowski M, Vorobiof D, Leonard R, Kennedy I, Azli N, Murawsky M, Riva A and Pouillart P: Docetaxel and doxorubicin compared with doxorubicin and cyclophosphamide as first-line chemotherapy for metastatic breast cancer: results of a randomized, multicenter, phase III trial. J Clin Oncol 21: 968-975, 2003.

11. Mackey JR, Martin M, Pienkowski T, Rolski J, Guastalla JP, Sami A, Glaspy J, Juhos E, Wardley A, Fornander T, Hainsworth J, Coleman R, Modiano MR, Vinholes J, Pinter T, Rodríguez-Lescure A, Colwell B, Whitlock P, Provencher L, Laing K, Walde D, Price C, Hugh JC, Childs BH, Bassi K, Lindsay MA, Wilson V, Rupin M, Houé V and Vogel C: Adjuvant docetaxel, doxorubicin, and cyclophosphamide in node-positive breast cancer: 10-year follow-up of the phase 3 randomised BCIRG 001 trial. Lancet Oncol 14: 72-80, 2013.

12. Sachelarie I, Grossbard ML, Chadha M, Feldman S, Ghesani M and Blum RH: Primary systemic therapy of breast cancer. Oncologist 11: 574-589, 2006.

13. Sánchez-Muñoz A, Plata-Fernández YM, Fernández M, Jaén-Morago A, Fernández-Navarro M, de la Torre-Cabrera C, Ramirez-Tortosa C, Lomas-Garrido M, Llácer C, Navarro-Perez V, Alba-Conejo E and Sánchez-Rovira P: The role of immunohistochemistry in breast cancer patients treated with neoadjuvant chemotherapy: an old tool with an enduring prognostic value. Clin Breast Cancer 13: 146-152, 2013.

14. Untch M, Fasching PA, Konecny GE, Hasmüller S, Lebeau A, Kreienberg R, Camara O, Müller V, du Bois A, Kühn T, Stickeler E, Harbeck N, Höss C, Kahlert S, Beck T, Fett W, Mehta KM, von Minckwitz G and Loibl S: Pathologic complete response after neoadjuvant chemotherapy plus trastuzumab predicts favorable survival in human epidermal growth factor receptor 2-overexpressing breast cancer: results from the TECHNO trial of the AGO and GBG study groups. J Clin Oncol 29: 3351-3357, 2011.

15. Church DN and Talbot DC: Survivin in solid tumors: rationale for development of inhibitors. Curr Oncol Rep 14: 120-128, 2012.

16. Altieri DC: Survivin, cancer networks and pathway-directed drug discovery. Nat Rev Cancer 8: 61-70, 2008.

17. Sprenger T, Rodel F, Beissbarth T, Conradi LC, Rothe H, Homayounfar K, Wolff HA, Ghadimi BM, Yildirim M, Becker H Rödel C and Liersch T: Failure of downregulation of survivin following neoadjuvant radiochemotherapy in rectal cancer is associated with distant metastases and shortened survival. Clin Cancer Res 17: 1623-1631, 2011.

18. Petrarca CR, Brunetto AT, Duval V, Brondani A, Carvalho GP and Garicochea B: Survivin as a predictive biomarker of complete pathologic response to neoadjuvant chemotherapy in patients with stage II and stage III breast cancer. Clin Breast Cancer 11: 129-134, 2011.
19. Gerdes J, Schwab U, Lemke H and Stein H: Production of a mouse monoclonal antibody reactive with a human nuclear antigen associated with cell proliferation. Int J Cancer 3: 13-20, 1983.

20. Urruticoechea A, Smith IE and Dowsett M: Proliferation marker Ki-67 in early breast cancer. J Clin Oncol 23: 7212-7220, 2005.

21. de Azambuja E, Cardoso F, de Castro G Jr, Colozza M, Mano MS Durbecq V, Sotiriou C, Larsimont D, Piccart-Gebhart MJ and Paesmans M: Ki-67 as prognostic marker in early breast cancer: a meta-analysis of published studies involving 12,155 patients. Br J Cancer 96: 1504-1513, 2007.

22. Stuart-Harris R, Caldas C,Pinder SE and Pharaoh P: Proliferation markers and survival in early breast cancer: a systematic review and meta-analysis of 85 studies in 32,825 patients. Breast 17 : 323-334, 2008.

23. Colleoni M, Viale G, Zahrieh D, Bottiglieri L, Gelber RD, Veronesi P,Balduzzi A, Torrisi R, Luini A,Intra M, Dellapasqua S, Cardillo A, Ghisini R, Peruzzotti G and Goldhirsch A: Expression of ER, PgR, HER1, HER2, and response: a study of preoperative chemotherapy. Ann Oncol 19: 465-472, 2008.

24. Colleoni M, Viale G, Zahrieh D, Pruneri G, Gentilini O, Veronesi P, Gelber RD, Curigliano G, Torrisi R, Luini A, Intra M, Galimberti V, Renne G, Nolè F, Peruzzotti G and Goldhirsch A: Chemotherapy is more effective in patients with breast cancer not expressing steroid hormone receptors: a study of preoperative treatment. Clin Cancer Res 10: 6622-6628, 2004.

25. Wang L, Jiang Z, Sui M, Shen J, Xu C and Fan W: The potential biomarkers in predicting pathologic response of breast cancer to three different chemotherapy regimens: a case control study. BMC Cancer 9: 226, 2009.

26. Xu C, Yamamoto-Ibusuki M, Yamamoto Y, Yamamoto S, Fujiwara S, Murakami K, Okumura Y, Yamaguchi L, Fujiki Y and Iwase $\mathrm{H}$ : High survivin mRNA expression is a predictor of poor prognosis in breast cancer: a comparative study at the mRNA and protein level. Breast Cancer: Sep 12, 2012 (Epub ahead of print).

27. Lee J, Im YH, Lee SH, Cho EY, Choi YL, Ko YH, Kim JH, Nam SJ, Kim HJ, Ahn JS, Park YS, Lim HY, Han BK and Yang JH: Evaluation of ER and Ki-67 proliferation index as prognostic factors for survival following neoadjuvant chemotherapy with doxorubicin/docetaxel for locally advanced breast cancer. Cancer Chemother Pharmacol 61: 569-577, 2008.

28. Ryan BM, Konecny GE, Kahlert S, Wang HJ, Untch M, Meng G, Pegram MD, Podratz KC, Crown J, Slamon DJ and Duffy MJ: Survivin expression in breast cancer predicts clinical outcome and is associated with HER2, VEGF, urokinase plasminogen activator and PAI-1. Ann Oncol 17: 597-604, 2006. 